\title{
PID control parameters optimization for temperature calibration laboratory
}

\author{
Michal Voldán ${ }^{1, a}$ and Radek Strnad ${ }^{2}$ \\ 1, 2 Czech Metrology Institute, Radiová 3, 10200 Prague, Czech Republic
}

\begin{abstract}
PID controllers are the most widespread types of controllers and are necessary for controlling furnaces and baths in temperature calibration laboratory. They are quite difficult to tune, but there are dozens of different tuning schemes, each working slightly better or worse depending on the type of system that is controlled; there is no perfect tuning scheme. One of the best known method is called the Ziegler-Nichols method. It works quite well on a large number of systems and does not require extensive system testing or measurement beforehand. Systems are described by non-linear differential equations and general solving is almost impossible. This is the main reason why the local linearization in the working temperature is needed. It leads to create of the PID parameters table for each measurement point. Investigated device was modeled in the Simulink environment and the theoretical behavior after application of the Ziegler-Nichols method was compared with the results for several other methods. These results was also compared to the measured data of the real behavior of the system. Based on the results comparison, there could be proposed a simple way to optimize PID control parameters of most of the furnaces and baths in the temperature calibration laboratory.
\end{abstract}

Keywords: PID parameters, Ziegler-Nichols method

\section{Introduction}

Currently, PID controllers dominate in the most of industrial control circuits. These controllers are in many cases kept in their original setting throughout their use although the properties of the controlled system and its inner sensor changes over time. Users often don't know about possibilities of optimizing the system. The consequences of inappropriate PID parameters setting are then mistakenly considered to be properties of the controlled system. Another reason can be fear of difficult and time-consuming optimizing procedure application without any guarantee of the satisfactory result. None of the procedures is universal so for each system, different procedure can be optimal.

The objective of this work is therefore to show the procedure for quite quick selection between several simplest and most used methods of optimization the proper one. To make this possible, it is necessary to select the nominal temperature value at which the behavior of the calibration furnace or bath should be optimized. It is necessary to realize, that the system will probably behave at each temperature slightly different. We also have to count with the fact that the properties of the system will differ for various media (for example in case of exchanging block in the furnace or liquid in bath).

According to the analysis of so called "transient response" of the system there could be preliminary estimated, how much the investigated methods will lead to the feasible state. The correctness of the transient response analysis will affect the difference between the simulation and real system behavior.

\section{Methods and assumptions}

All the methods used for proposing the PID control parameters are based on the computer model of the investigated system that has been created in the Simulink environment. As a tested device there has been selected "511 Medusa - 3, Isotech" furnace with a theoretical range of realizable temperature values from $30{ }^{\circ} \mathrm{C}$ to $700{ }^{\circ} \mathrm{C}$. Selected nominal temperature value is $230^{\circ} \mathrm{C}$, because this was assumed to be problematic from the optimization point of view. To enable the model to approximately describe the furnace behavior the initial measurement of the transient response was necessary. After analysis of this response the transfer function of the furnace at $230{ }^{\circ} \mathrm{C}$ is calculated so the model is complete.

The model enables to examine the system under different PID setting conditions in much shorter time than in case of real measurements. The optimization methods have been tested on a model and compared with measurements results. This comparison ensures reliability of the model, but the modeled results still should be always checked.

\section{Model of the furnace}

For the purpose of the furnace behavior simulation at the nominal temperature, it is necessary to measure the temperature response of the device on the step change of the input heating power. The response curve is then analyzed according to the [1] as shown on Figure 1. At first, the inflexion point (red dot) is computed to obtain values of constants $A$ and $B$, which are used for the purpose of transfer function of the system, according to the following equation:

$$
H(p)=\frac{K}{(A \cdot p+1)(B \cdot p+1)}
$$

a Corresponding author: mvoldan@cmi.cz 
where $K$ marks the change of the systems temperature and complex variable $p$ is input variable in the Laplace domain.

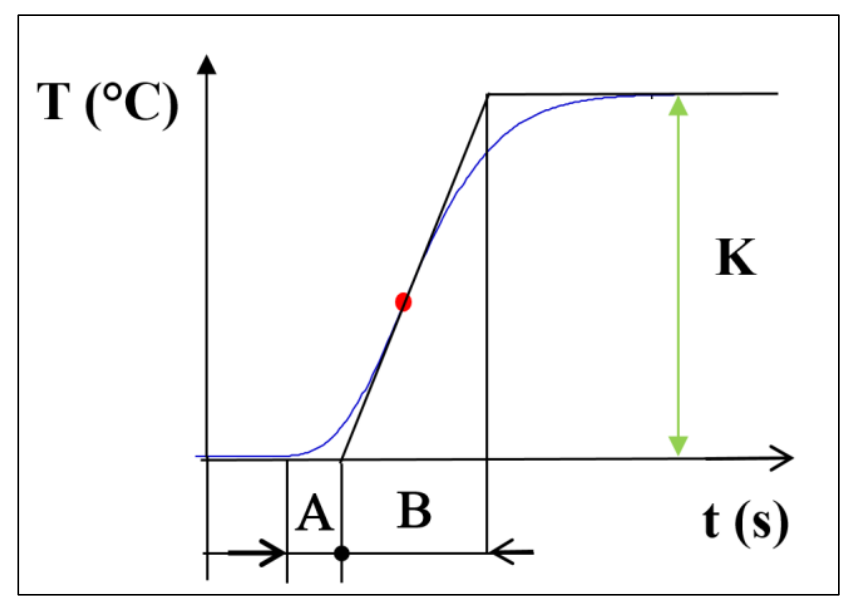

Figure 1. Typical transient response [1].

Analysis of the transient response is provided by simple script written in the Matlab environment. It ensures more accurate identification of the constants $A$ and $B$ (Figure 2).

There are several pitfalls which should be carefully avoided during describing the model blocks. PID control parameters of the PID Controller block can be of different units than parameters of the real controller, used in the modeled device. There are also differences between controllers, where for one we can set the value of proportional component, while for the other one, we can set only the size of the proportional band. Also the Transfer Function block needs values of the constants $A$ and $B$ to be filled in the units of minutes and, in addition, the equation describing its behavior is represented in quite distinct form.

Other properties of this modified model described in [2] affect simulation results less significant (shift on the horizontal or vertical axe or multiplication of the output signal by some constant value), but the $K$ value still should be considered. The real furnace almost never starts heating from the temperature of $0{ }^{\circ} \mathrm{C}$, but very often from the ambient temperature (temperature of the laboratory).

One should be sure that all the input parameters are computed properly, so the simulation result would be very similar to the real measurement record from which the properties of the system are obtained.

Once the transfer function is properly computed, the model can be completed (Figure 3). [1, 2, 3, 5, 6]

\section{Testing of optimizing methods}

As an exemplary device for investigating the possibilities of reducing oscillations, minimalizing offset between wanted and real temperature value and ability of faster settling on feasible temperature, the "511 Medusa - 3, Isotech" furnace has been selected. As the nominal temperature, $230{ }^{\circ} \mathrm{C}$ was chosen. The main reason for selecting low temperature in relation to quite high temperature range was to save the settling time needed to achieve the final temperature.

All the characteristics was measured using the Pt 100 resistance thermometer (Ametek STS-100, IPRT) and thermometry bridge (ASL F300) with room temperature at the level of $(23 \pm 2.5){ }^{\circ} \mathrm{C}$.

Several methods has been tested to investigate how much (or if) the behavior of the simulated system will be optimized. Each method uses different way to propose the PID parameters but all of them can be tested on the model shown on Figure 3. The controllers Autotune function was also taken into account.

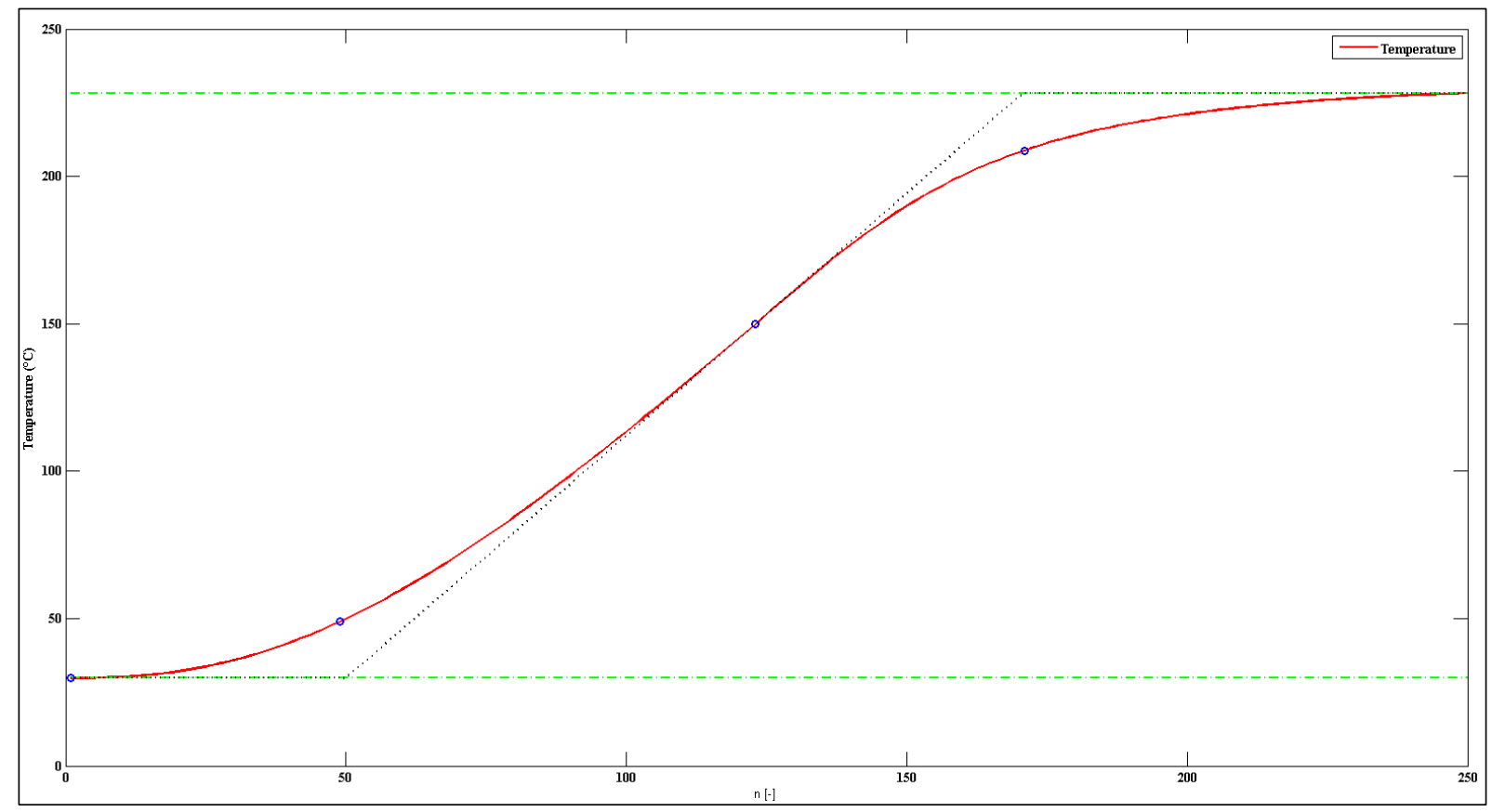

Figure 2. Initial transient response of the furnace [7]. 


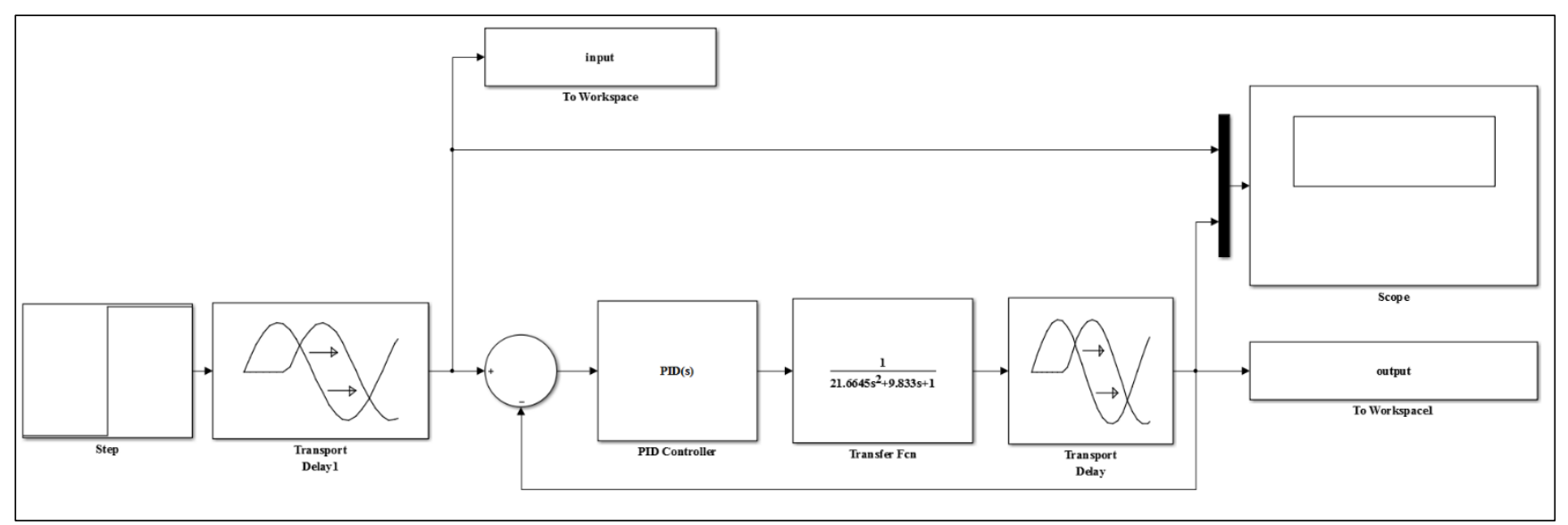

Figure 3. Model of the furnace created in the Simulink environment [3, 7].

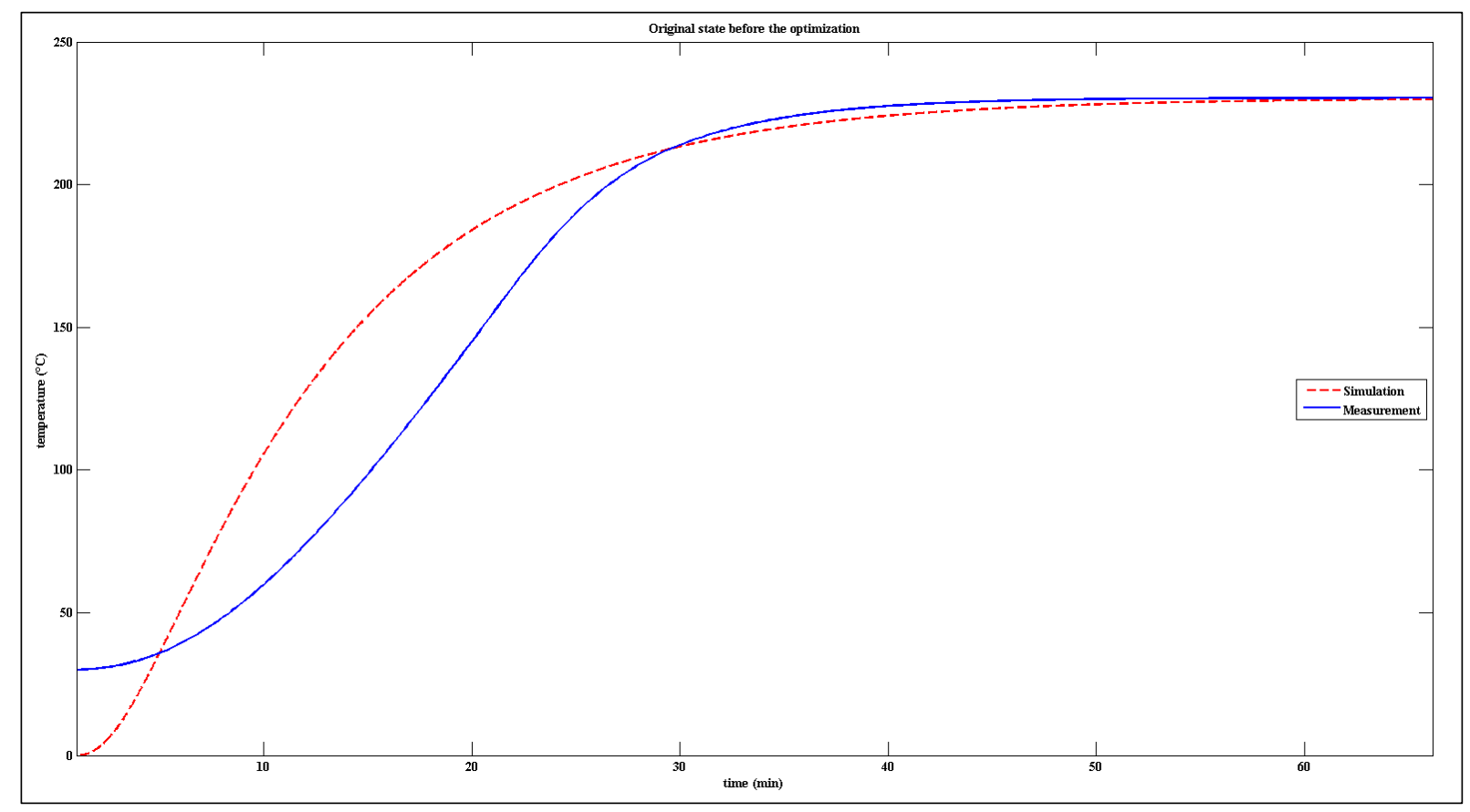

Figure 4. Original state before the optimization [7].

On the Figure 4 it is shown that the model differs from the measured device, it means that it is not perfectly describing the furnaces behavior. There are probably additional parameters which are not taken into account, and will be included in the following work. Simulation of the original state will always show us the quality of the model. $[1,3,4]$

\subsection{Ziegler-Nichols frequency method}

This tuning method, described in [2], is one of the most time-consuming method of all used in this work. The PID parameters are calculated from the characteristics of the furnace output signal (temperature) at the specific condition when the integral and derivate actions are turned off and proportional gain is set at the level, when the system just starts to oscillate. It can make this tuning method very discouraging and it is the time when the model is very useful.
The behavior of the furnace after applying proposed PID parameter values can differ for the simulation and for real measurement. It can be caused by wrong detection of the point, when the oscillations start (a possibility of making mistakes during oscillate-point detection is caused by the fact that the decision of the $P$ parameter value, when the oscillations appear is left to the furnace user). However, main characteristics of the output curves are very similar. These two curves differ mainly in the temperature value at which the system settles after some time. From an additional measurement, it was confirmed that also in case of the investigated furnace, the offset value grows with rising proportional band value, while modeled system settles always exactly at the feasible value. $[1,2,4,5]$ 


$$
D=\frac{A}{2}
$$

\subsection{Ziegler-Nichols evaluation of the transient response}

This is another Ziegler-Nichols tuning method, described in [2]. It uses transient response to propose the control parameters from its properties. These three parameters are set according to the following equations.

$$
\begin{aligned}
& P=1.2 \cdot \frac{1}{K} \cdot \frac{B}{A} \\
& I=2 \cdot A
\end{aligned}
$$

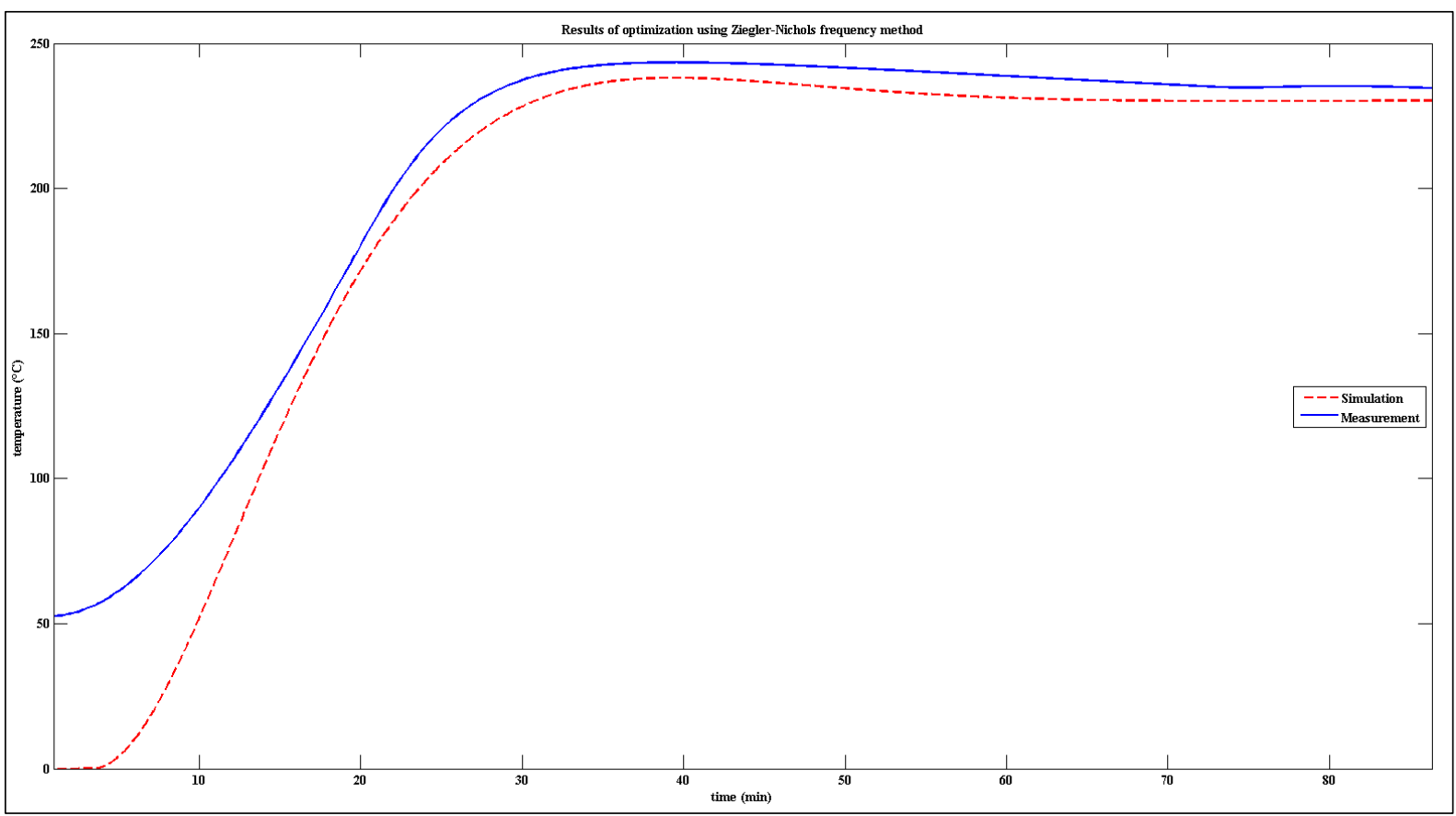

Figure 5. Results of optimization using Ziegler-Nichols frequency method [7].

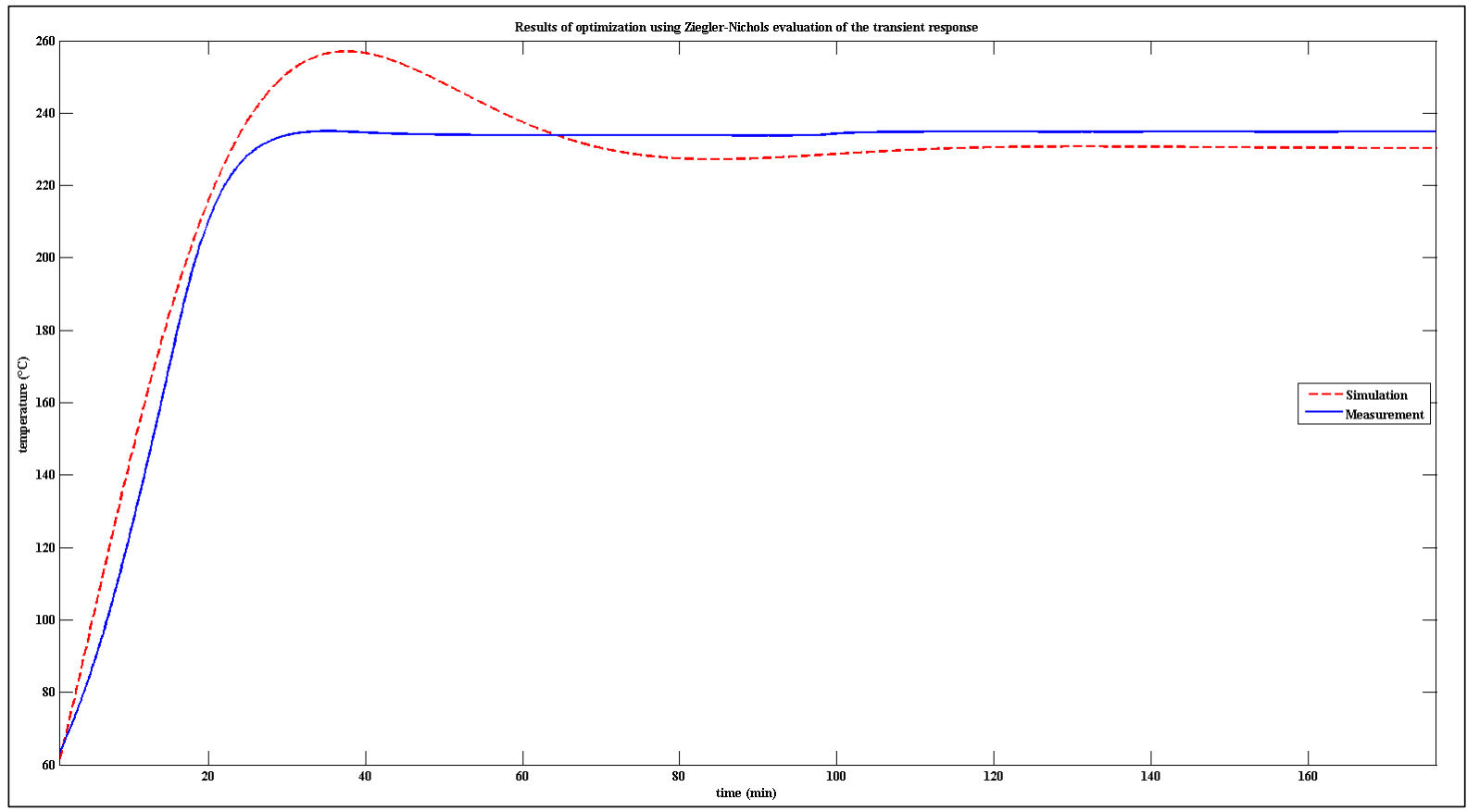

Figure 6. Results of optimization using Ziegler-Nichols evaluation of the transient response [7]. 


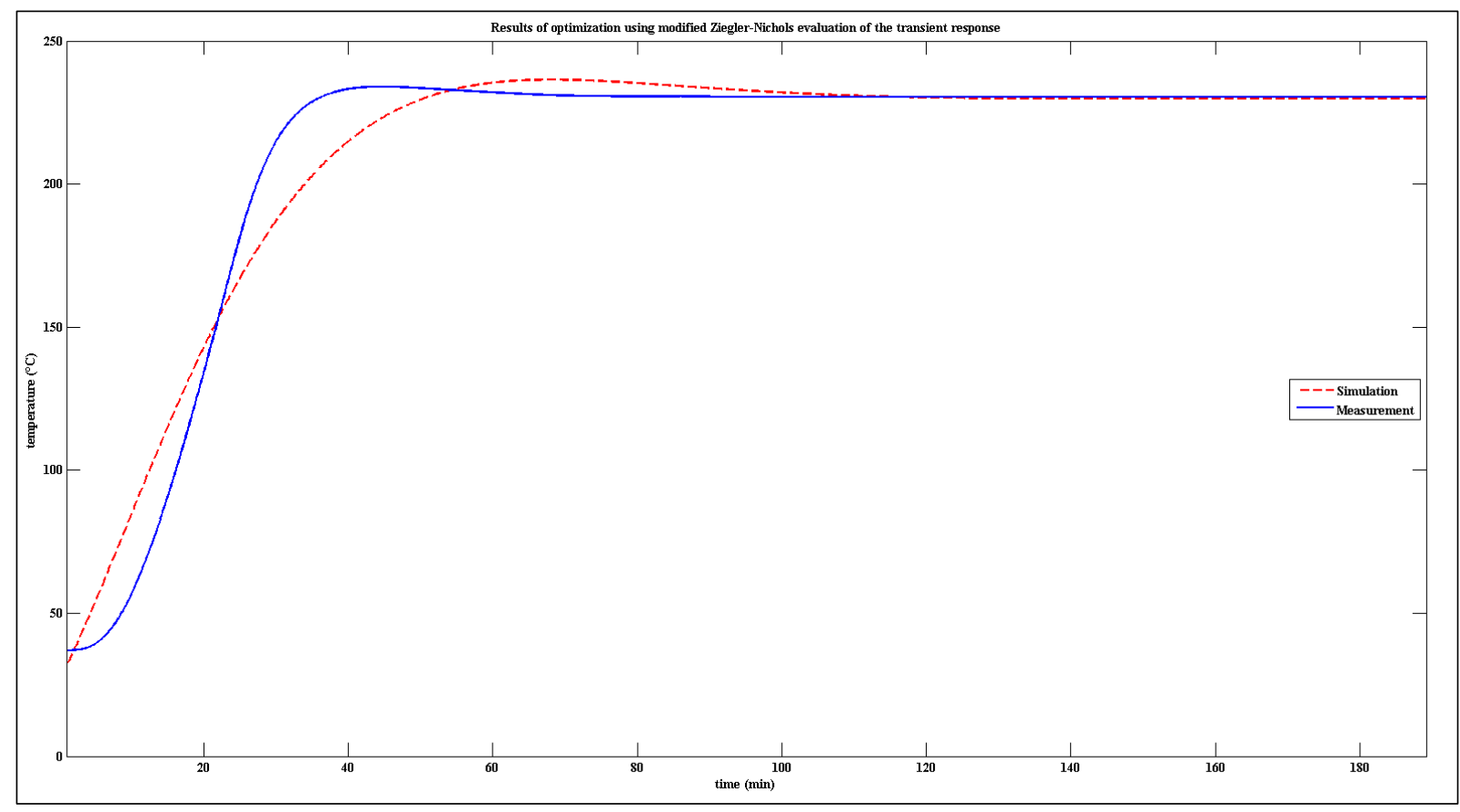

Figure 7. Results of optimization using modified Ziegler-Nichols evaluation of the transient response [7].

\subsection{Modified Ziegler-Nichols evaluation of the transient response}

This modification of the previous method of optimization is described in [4] and should lead to a smoother course of the systems output signal. According to the $[5,6]$, the first estimation of the optimization difficulty can be made using properties of the transient response, as follows:

- Well controllable system: $\frac{B}{A}<\frac{1}{10}$

- Controllable: $\quad \frac{B}{A} \approx \frac{1}{6}$

- Hard controllable: $\quad \frac{B}{A}>\frac{1}{3}$

Resulting equations for PID parameters then depend on this ratio value:

- For $\frac{B}{A}<0.33$

$$
\begin{aligned}
P & =\frac{5}{9} \frac{B}{K \cdot A} \\
I & =5 \cdot A \\
D & =\frac{A}{2}
\end{aligned}
$$

- $\quad$ For $\quad \frac{B}{A} \geq 0.33$

$$
\begin{aligned}
P & =\frac{B}{2 \cdot K \cdot A} \\
I & =B \\
D & =\frac{A}{2}
\end{aligned}
$$

As it is visible from the Figure 7, this method leads to quite satisfactory result. The simulation and measurement results seem to have very similar properties after some time. $[5,6]$

\subsection{Balanced settings}

The result of this optimization [6] should be a compromise between fast and robust control process. If we define normalized transport delay $\tau$ as:

$$
\tau=\frac{A}{A+B}
$$

then the components of the control loop can be computed as:

$$
\begin{aligned}
P & =\frac{1}{K}\left(1-\frac{2 \cdot \tau}{1+\sqrt{1+2 \cdot \tau^{2}}}\right) \\
I & =(A+B) \cdot\left(\frac{1+\sqrt{1+2 \cdot \tau^{2}}}{2}-\tau\right) \\
D & =\frac{I}{4}
\end{aligned}
$$




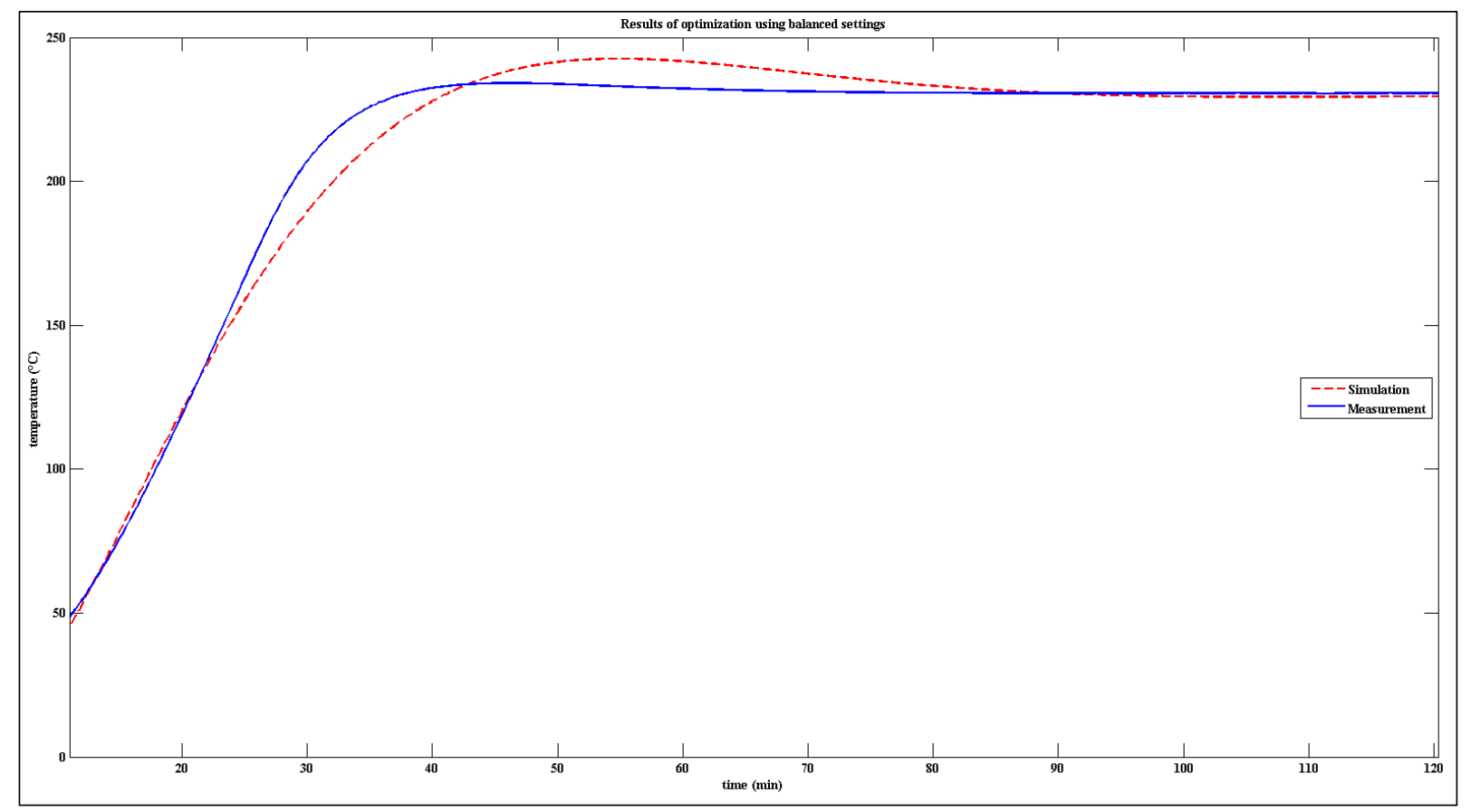

Figure 8. Results of optimization using balanced settings [7].

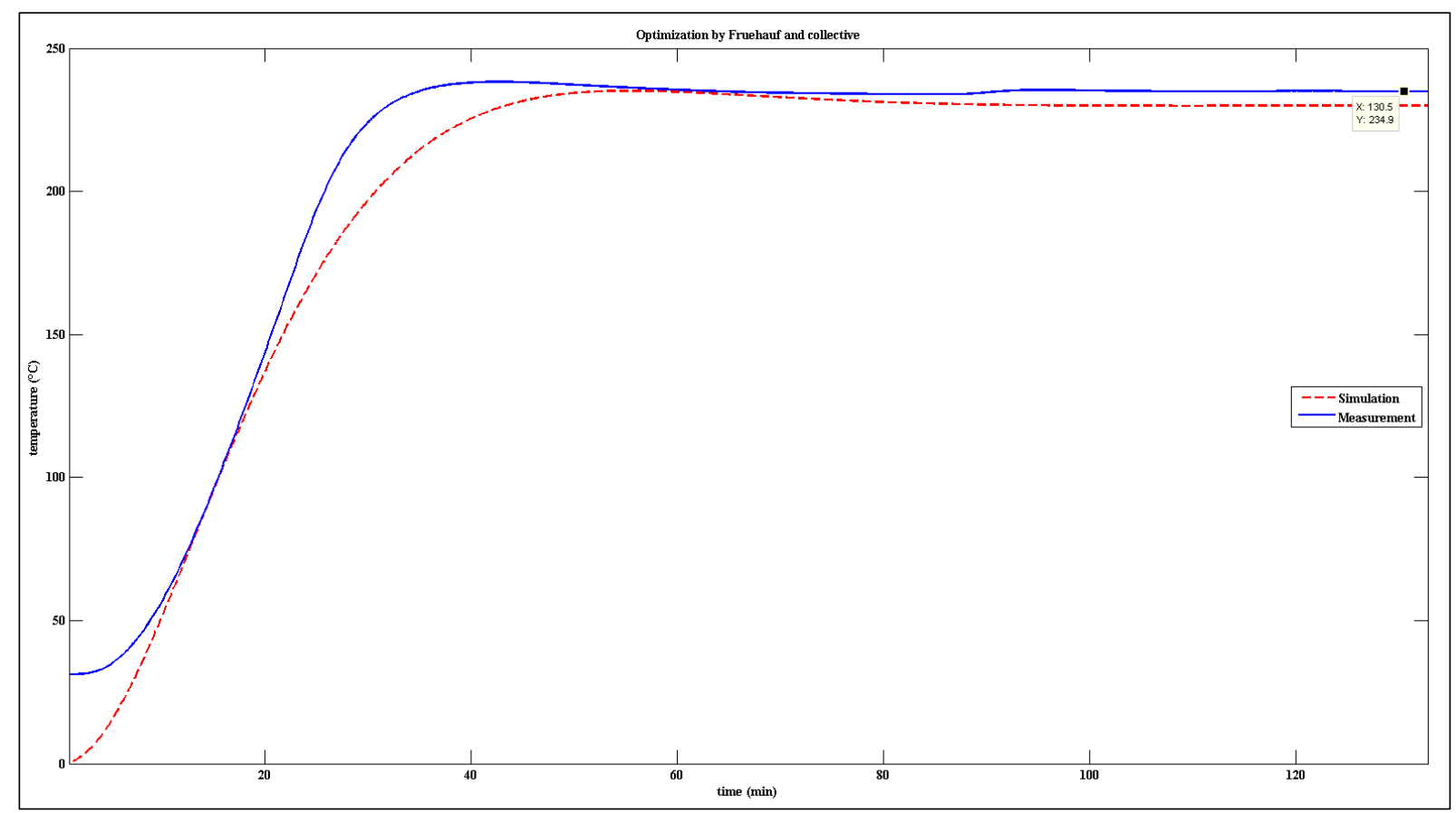

Figure 9. Optimization by Fruehauf and collective [7].

\subsection{Optimization by Fruehauf and collective}

The proposed control parameters are dependent only on constants derived from the transient characteristic:

$$
\begin{aligned}
P & =\frac{B}{2 \cdot A} \\
I & =B \\
D & =\frac{A}{2}
\end{aligned}
$$

This method is very similar to the Modified ZieglerNichols evaluation of the transient response, but the $K$ parameter is not included into the procedure, so the results for furnace and its model can significantly differ. [6] 


\subsection{Optimization by Aström and Hägglund}

The result of this optimization procedure are very similar for the model and real furnace. The control parameters values are very sensitive to a proper evaluation of the transient characteristic (but less sensitive than the balanced settings method). The parameters are computed according to the following equations $[1,6]$ :

$$
\begin{aligned}
P & =3.8 \cdot \frac{B}{K \cdot A} \cdot e^{\left(-8.4 \cdot \tau+7.3 \cdot \tau^{2}\right)} \\
I & =5.2 \cdot A \cdot e^{\left(-2.5 \cdot \tau-1.4 \cdot \tau^{2}\right)} \\
D & =0.89 \cdot A \cdot e^{\left(-0.37 \cdot \tau-4.1 \cdot \tau^{2}\right)}
\end{aligned}
$$

\subsection{Optimization using the Autotune function}

The Autotune function is implemented in almost all modern controllers as a basic way to optimize the furnace. The success of the optimization depends mainly on the procedure that is sometimes the manufacturer's secret and the quality of the furnaces inner sensor (Figure 11).

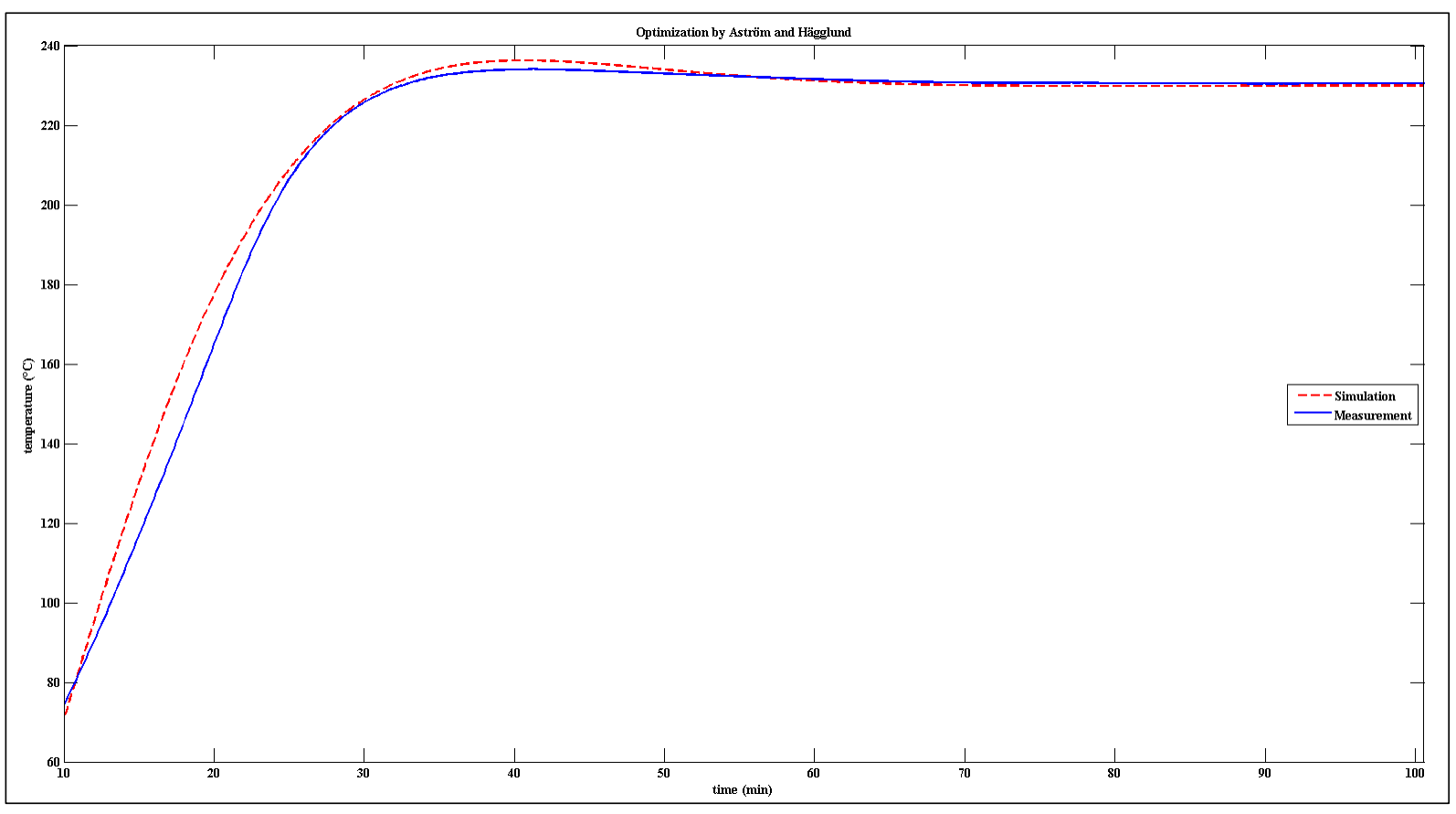

Figure 10. Optimization by Aström and Hägglund [7].

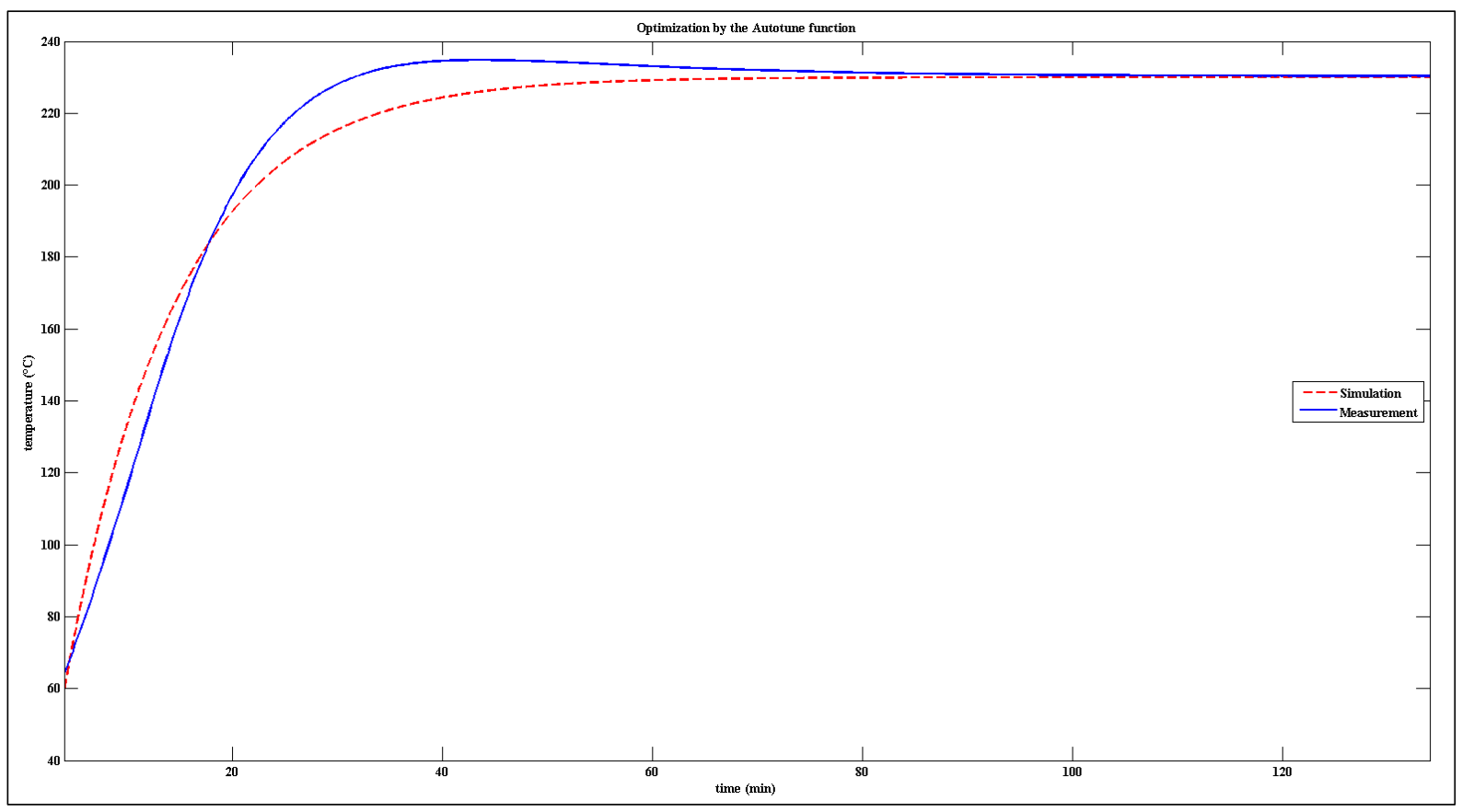

Figure 11. Optimization by the Autotune function [7]. 


\section{Results}

This part includes summary of the properties of the furnace before and after optimization procedures application. These properties are the settling time, temperature instability and offset.

Settling time is here defined as the time when the output signal has no definite trend and the temperature value starts oscillating around some mean value (which is changing no more than in order of few $\mathrm{mK}$ per hour).

Temperature instability is here the variance of the output signal for some period of 30 minutes after the state of the settling.

Offset is here the difference between the measured mean temperature value (when the furnace temperature is settled) and the setpoint value (temperature value set on the controller).

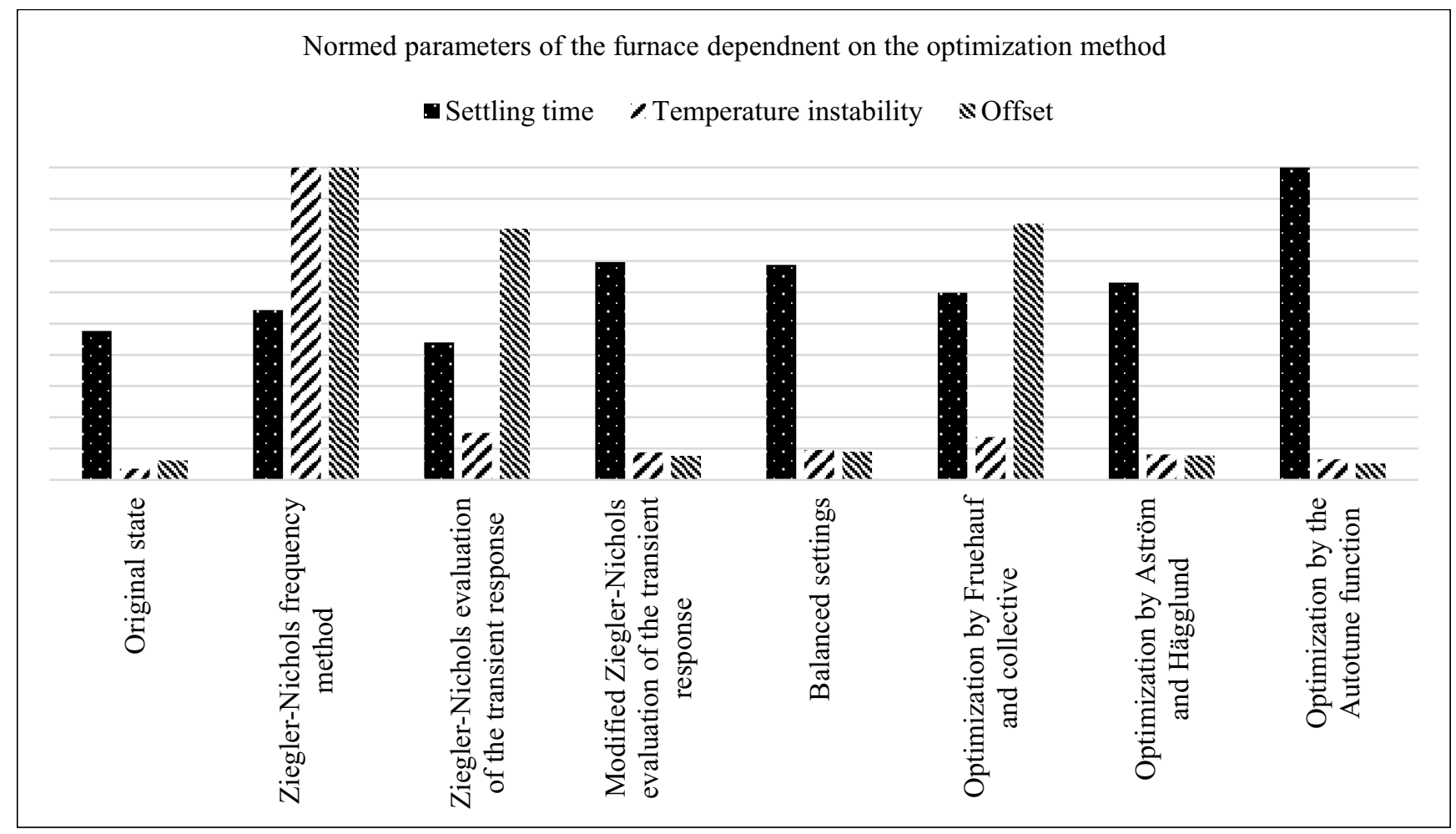

Figure 12. Normed parameters of the furnace before and after optimization procedures application.

Table 1. Parameters of the furnace before and after optimization processes application.

\begin{tabular}{|c|c|c|c|}
\hline Method of optimization & $\begin{array}{c}\text { Settling time } \\
{[\mathrm{h}: \mathrm{mm}]}\end{array}$ & $\begin{array}{c}\text { Temperature } \\
\text { instability }\left[{ }^{\circ} \mathrm{C}\right]\end{array}$ & $\begin{array}{c}\text { Offset } \\
{\left[{ }^{\circ} \mathrm{C}\right]}\end{array}$ \\
\hline Original state & 1:07 & 0.025 & 0.380 \\
\hline Ziegler-Nichols frequency method & $1: 17$ & 0.701 & 6.166 \\
\hline Ziegler-Nichols evaluation of the transient response & $1: 02$ & 0.105 & 4.954 \\
\hline $\begin{array}{l}\text { Modified Ziegler-Nichols evaluation of the transient } \\
\text { response }\end{array}$ & $1: 38$ & 0.062 & 0.474 \\
\hline Balanced settings & $1: 37$ & 0.067 & 0.557 \\
\hline Optimization by Fruehauf and collective & $1: 25$ & 0.096 & 5.062 \\
\hline Optimization by Aström and Hägglund & $1: 29$ & 0.057 & 0.481 \\
\hline Optimization by the Autotune function & $2: 21$ & 0.046 & 0.323 \\
\hline
\end{tabular}

\section{Conclusion}

Even though the Ziegler-Nichols frequency method is said to be one of the simplest method of optimization, for the investigated furnace it leads to the worst results in comparison to other procedures. The Autotune function leads to quite satisfactory results but enlarges the settling time. For the fastest settling at the feasible temperature 
value can be used the Ziegler-Nichols evaluation of the transient response and the lowest instability value can be achieved by using the original configuration.

It can be said that the original configuration leads to a best properties of the system of all the methods used in this work. When none of the methods leads to better results but also the original configuration doesn't provide satisfying results, we should add another method and apply it to the model. It will provide us preliminary information if it is convenient to use the chosen method.

This work is proposing a simple method to accelerate the optimizing process for general furnace (or bath) with PID controller. This can lead to faster reduction of the uncertainty level in the calibration laboratories.

\section{References}

[1] SCHLEGEL, M.: PID regulátory: problémy teorie a praxe. Faculty of applied sciences, UWB, Plzeň.

URL: www.kvetakov.net/ koza/pid/schlegel

[2] SCHLEGEL, M.: PRŮMYSLOVÉ PID REGULÁTORY: TEORIE PRO PRAXI. Faculty of applied sciences, UWB, Plzeň.

URL: http://zcu.arcao.com/kky/zky/Pragol.pdf

[3] BHAT, R.: Time and Frequency Response Analysis of PID Controller. NMIMS, Mukesh Patel School of Technology Management and Engineering, Shirpur.

URL:

https://www.academia.edu/7793138/Time_and_Frequency_Respons e_Analysis_of_PID_Controller

[22.5.2015]

[4] MSL Technical Guide 20: Introduction to Temperature Control. Measurement Standards of New Zealand.

URL: https://www.msl.irl.cri.nz/sites/all/files/trainingmanuals/TG20-July-2009.pdf

[5] KMINEK: REGULACE: Část 1: Spojitá regulace. Ústav počítačové a ř́idicí techniky, VŠCHT, Praha.

URL: http://moodle.vscht.cz/file.php/78/PRS-10-reg_1.pdf

[6] KLÁN, P.: Moderní metody nastavení PID regulátorů, Č́st I: Procesy s přechodovou charakteristikou typu „S”. Automa 6 (2000), č. 9, str. 54-57.

URL: http://automa.cz/download/au090054.pdf

[14.2.2015]

[7] MATLAB \& SIMULINK. Version 7.12.0.635 (R2011a), 32-bit. 